See Article page $\mathrm{XXX}$.

\section{Commentary: Endovascular repair in Marfan syndrome: Viable bailout but not ready for prime time}

\author{
Rodolfo V. Rocha, MD, PhD, ${ }^{\text {a }}$ \\ Maral Ouzounian, $\mathrm{MD}, \mathrm{PhD},{ }^{\mathrm{b}}$ and \\ Stephen E. Fremes, MD, MSc ${ }^{a}$
}

Thoracic endovascular aortic repair (TEVAR) has evolved to become standard of care for patients with degenerative aortic disease of the descending thoracic aorta, blunt aortic injury, and complicated type B aortic dissection (TBAD). ${ }^{1}$ Advantages include ease of implantation, less surgical trauma and physiological derangements, and lower early morbidity and mortality compared with open distal aortic repair. $^{2}$ Nonetheless, TEVAR has been associated with an increased risk of aortic-related reinterventions. ${ }^{3}$

Patients with hereditary thoracic aortic disorders (HTAD), including Marfan syndrome, are considered to have a relative contraindication for TEVAR. ${ }^{1}$ Despite reasonable perioperative success, significant concerns arise in mid to late follow-up. Complications, including endoleak, aortic reintervention, stent migration, and retrograde type A dissection, all occur at substantially higher rates than in patients without HTAD. ${ }^{4,5}$ Although Jiang and colleagues ${ }^{6}$ reported good early success and late survival in 26 patients with TBAD treated with TEVAR over a period of 10 years, endoleaks occurred in $27 \%$ of patients and they observed a $50 \%$ reintervention rate at 10 years. Furthermore, of patients who died during follow-up, $50 \%$ had an aortic-related death. The authors' experience provides a

\footnotetext{
From the ${ }^{\mathrm{a}}$ Division of Cardiac Surgery, Department of Surgery, Schulich Heart Centre, Sunnybrook Health Sciences Centre, and ${ }^{\mathrm{b}}$ Division of Cardiovascular Surgery, Peter Munk Cardiac Centre, University Health Network, University of Toronto, Toronto, Ontario, Canada.

Disclosures: The authors reported no conflicts of interest.

The Journal policy requires editors and reviewers to disclose conflicts of interest and to decline handling or reviewing manuscripts for which they may have a conflict of interest. The editors and reviewers of this article have no conflicts of interest.

Received for publication June 14, 2021; revisions received June 14, 2021; accepted for publication June 15, 2021.

Address for reprints: Stephen E. Fremes, MD, MSc, Division of Cardiac Surgery, Schulich Heart Centre, University of Toronto, 2075 Bayview Ave, Room H4 05, Toronto, ON M4N 3M5 Canada (E-mail: stephen.fremes@sunnybrook.ca).

J Thorac Cardiovasc Surg 2021; $\mathbf{\square}: 1-2$

$0022-5223 / \$ 36.00$

Copyright (C) 2021 by The American Association for Thoracic Surgery

https://doi.org/10.1016/j.jtcvs.2021.06.021
}

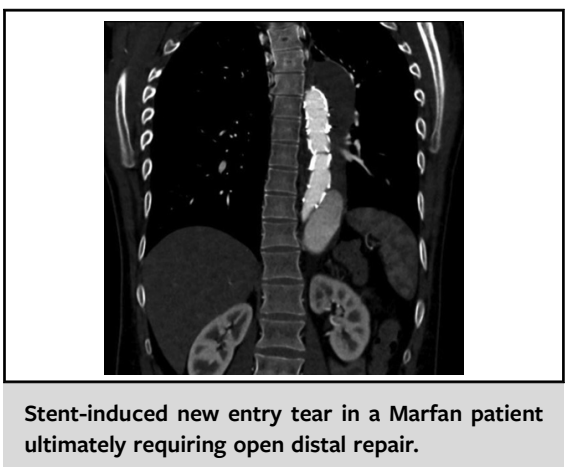

\author{
CENTRAL MESSAGE \\ Endovascular repair for type B \\ dissection is a viable bailout \\ strategy, but demands lifelong \\ surveillance in patients with he- \\ reditary thoracic aortic \\ disorders.
}

cautionary tale about the malignant natural history of stent-induced new entry tears in patients with HTAD and highlights the importance of lifelong surveillance of these patients, particularly those with a patent false lumen after TEVAR.

The authors did not discuss what led them to select an endovascular approach for these young patients with Marfan syndrome. Although some studies have reported high rates of morbidity and mortality with open distal aortic repair, particularly when analyzing regional or national registries, centers of excellence provide excellent results for open repair for patients with HTAD. ${ }^{7}$ In the GenTAC registry, operative mortality following open thoracoabdominal aortic repair in patients with HTAD was $1.3 \%{ }^{7}$; Coselli and colleagues ${ }^{8}$ reported an operative mortality of $4 \%$ in patients with Marfan syndrome undergoing distal aortic repair for dissection.

We agree that TEVAR may be used as an emergency bailout procedure in patients with HTAD and lifethreatening complications such as rupture, malperfusion, or aorto-enteric or bronchial fistulas. Furthermore, TEVAR is an excellent option when landing in graft proximally and distally, such as in patients with intercostal patch aneurysms. We do not think endovascular repair with fenestrated or branch grafts for the arch or thoracoabdominal aorta is a viable option given the fragile aortic tissue, and risk of branch vessel complications in these patients. If TEVAR is to be used in HTAD, the following principles should be 
applied: excluding stent grafts with bare stents and barbs; landing in a preexisting graft or a long segment of nondilated native aorta; minimizing oversizing; and avoiding balloon dilatation.

Despite their encouraging results, we agree with the authors that TEVAR for TBAD in patients with Marfan syndrome should only be used in those who are at high or prohibitive risk for open repair and with suitable anatomy for TEVAR. If TEVAR is performed in these patients, closer surveillance should occur, particularly if false lumen thrombosis is not achieved.

\section{References}

1. Czerny M, Pacini D, Aboyans V, Al-Attar N, Eggebrecht H, Evangelista A, et al. Current options and recommendations for the use of thoracic endovascular aortic repair in acute and chronic thoracic aortic disease: an expert consensus document of the European Society for Cardiology (ESC) Working Group of Cardiovascular Surgery, the ESC Working Group on Aorta and Peripheral Vascular Diseases, the European Association of Percutaneous Cardiovascular Interventions (EAPCI) of the ESC and the European Association for Cardio-Thoracic Surgery (EACTS). Eur J Cardiothorac Surg. 2021;59:65-73.

2. Czerny M, Pacini D, Aboyans V, Al-Attar N, Eggebrecht H, Evangelista A, et al. Clinical cases referring to current options and recommendations for the use of thoracic endovascular aortic repair in acute and chronic thoracic aortic disease: an expert consensus document of the European Society for Cardiology (ESC) Working Group of Cardiovascular Surgery, the ESC Working Group on Aorta and Peripheral Vascular Diseases, the European Association of Percutaneous Cardiovascular Interventions (EAPCI) of the ESC and the European Association for Cardio-Thoracic Surgery (EACTS). Eur J Cardiothorac Surg. 2021;59:74-9.

3. Zhang L, Zhao Z, Chen Y, Sun Y, Bao J, Jing Z, et al. Reintervention after endovascular repair for aortic dissection: a systematic review and meta-analysis. $J$ Thorac Cardiovasc Surg. 2016;152:1279-88.

4. Eid-Lidt G, Gaspar J, Melendez-Ramirez G, Cervantes SJ, González-Pacheco H, Dámas de Los Santos F, et al. Endovascular treatment of type B dissection in patients with Marfan syndrome: mid-term outcomes and aortic remodeling. Catheter Cardiovasc Interv. 2013;82:E898-905.

5. Harky A, Hussain SMA, MacCarthy-Ofosu B, Ahmad MU. The role of thoracic endovascular aortic repair (TEVAR) of thoracic aortic diseases in patients with connective tissue disorders-a literature review. Braz J Cardiovasc Surg. 2020; 35:977-85.

6. Jiang X, Chen B, Jiang J, Shi Y, Ma T, Fu W, et al. Outcomes of endovascular therapy for Stanford type B aortic dissection in patients with Marfan syndrome. J Thorac Cardiovasc Surg. 2021. XXX:XXX.

7. Frankel WC, Song HK, Milewski RK, Shalhub S, Pugh NL, Eagle KA, et al. Open thoracoabdominal aortic repair in patients with heritable aortic disease in the GenTAC Registry. Ann Thorac Surg. 2020;109:1378-84.

8. Coselli JS, Green SY, Price MD, Hash JA, Ouyang Y, Volguina IV, et al. Results of open surgical repair in patients with Marfan syndrome and distal aortic dissection. Ann Thorac Surg. 2016;101:2193-201. 